\title{
Features of the integrated development of the territory of the settlement
}

\author{
Kristina Merkuryeva ${ }^{1 *}$, and Alexander Kryakhtunov ${ }^{1}$ \\ ${ }^{1}$ Federal State Budget Educational Institution of Higher Education «Industrial University of \\ Tyumen», 625000, 38 st. Volodarsky, Tyumen, Russia
}

\begin{abstract}
Since the city is a historically developed complex system, the development of its territory in the existing buildings requires a detailed study and consideration of all the features of the territories within the boundaries of the element of the planning structure (quarter, microdistrict) or its parts. Urban planning activity in the city is carried out in accordance with the developed and approved urban planning documentation. In the process of exercising the authority by the municipality in the field of urban development, when changing strategic directions, setting new tasks, and changing the economic situation, it becomes necessary to amend the urban planning documentation. The presence of a set of documents of territorial planning and urban planning zoning allows to increase the investment attractiveness of the city territory, ensures transparency of adopted urban planning decisions, on the basis of which, any interested person can choose the direction of development of a particular territory. Therefore, the development of the urban environment should be carried out in a comprehensive manner, taking into account all areas of development and features of the territory and take into account the changes arising in the process of urban planning, including in urban planning documentation.
\end{abstract}

\section{Introduction}

Urban planning is a broad and diverse in its content creative activity, which, in turn, combines legislative regulation related to the construction and reconstruction of cities, national economic planning, engineering and architectural planning, organization and production of construction works.

Unlike the design of individual buildings and structures, the city cannot be designed in a completely finished form: it will continuously develop, like a living organism, expanding territorially and undergoing qualitative changes taking place in its planning, development and improvement. The urban area is divided into planning areas, the development of which determines the ultimate success and focus in the development of the city as a whole. The planning area is a large system of planning elements, the competent design and placement of which affects the dynamics of the urban environment.

However, it is important to realize that the development process of existing cities is extremely complex and entails considerable costs. Therefore, there is a need for the

\footnotetext{
${ }^{*}$ Corresponding author: chernyheg@tyuiu.ru
} 
implementation of integrated construction, which should not contradict the existing development, and at the same time, it must comply with the established state town-planning standards and rules, as well as building rules.

For the planned and integrated development of the territory of the city of Tyumen, a solution to the problems arising using a systematic approach to the regulation of urban development of the territory of the city of Tyumen, in particular the territories of planning areas of the city, is required. Partial inconsistencies arising between the General Plan of the city district and the Land Use and Development Rules of the city of Tyumen, as well as the lack of clear legal mechanisms for the implementation of promising decisions of the General Plan in the context of the existing development often leads to legal disputes, complicates the adoption of decisions on the development of certain territories, which significantly increases the preparatory time stage of investment construction projects (development of project documentation, obtaining permits).

The lack of approved territorial planning projects, the low level of provision of city territories with land surveying projects and, as a result, the lack of social facilities, public areas (squares, parks) and engineering support fixed in urban planning documentation impede the implementation of a comprehensive and planned development of the city, making it difficult to accept decisions on the use of individual land plots and leads to a decrease in the investment attractiveness of projects of building for investors.

In addition, the urgent problem for the city of Tyumen is the presence of unauthorized construction of capital construction facilities (without title documents or other permits). The presence of such objects impedes the implementation of managerial decisions on the development or development of the city's territories, leads to restrictions on the ability to provide the city's territory with social facilities, engineering and transport infrastructure and public areas.

The purpose of the study is to identify the features of the territory of the element of the 6th planning district "Central" of the city of Tyumen using the example of a land plot under the residential district "Right Bank" and adjacent land plots.

\section{Main part}

The division of the city into separate planning areas (urban, residential areas and neighborhoods) is carried out in accordance with urban planning documentation. Such a separation process involves a planning zoning process. This need is due to the desire to improve the system of public services through the organization of centers in each individual planning area. [8]

Under the planning area should be understood as the territory, which is an independent object of design work on the regional planning and urban planning. [7]

It is important to consider that the planning area is a fairly large planning unit. One of the features of the successful development and formation of a planning area is the systematic development of its individual parts, and, precisely, planning elements in compliance with the general concept of development of the entire planning area as a whole.

The territory of the city of Tyumen is divided into 19 planning areas, one of which is the 6th planning area "Central".

This planning area is one of the largest planning areas of the city of Tyumen, which occupies a central position and includes the historical part of the city. The boundaries of the planning area are the right bank of the river. Tour - st. Melnikaite - st. Permyakova on GP Trans-Siberian Railway - a log with the Tyumenka river bed. The area within the specified boundaries is 1708 ha. [4] 
In order to identify the features, an element of the planning area was considered - a land plot located in the city of Tyumen, along Barabinskaya Street with the territories adjacent to it.

According to Rosreestr, this land plot with an area of $80,136 \mathrm{~m}^{2}$ belongs to «TSZ» on the basis of ownership on the basis of a land purchase and sale agreement and has been granted for the placement of multi-storey residential buildings. The project of the Pravoberezhny microdistrict, for the construction of which this land plot was provided, involves the construction of 15 monolithic brick 19 houses with underground parking lots and commercial real estate.

According to a fragment of the planning project, in the territory of this microdistrict there will be provided a zone for residential development, a zone for educational purposes and a zone for trade purposes and public catering. Currently, this land plot borders on 19 adjacent land plots, as evidenced by the explication of land issued by the Department of Land Relations and Urban Planning of the Administration of the city of Tyumen, which in turn is heterogeneous in use and ownership. Therefore, it is important to note that there is a need to bring the surrounding area in accordance with the approved project planning of the territory.

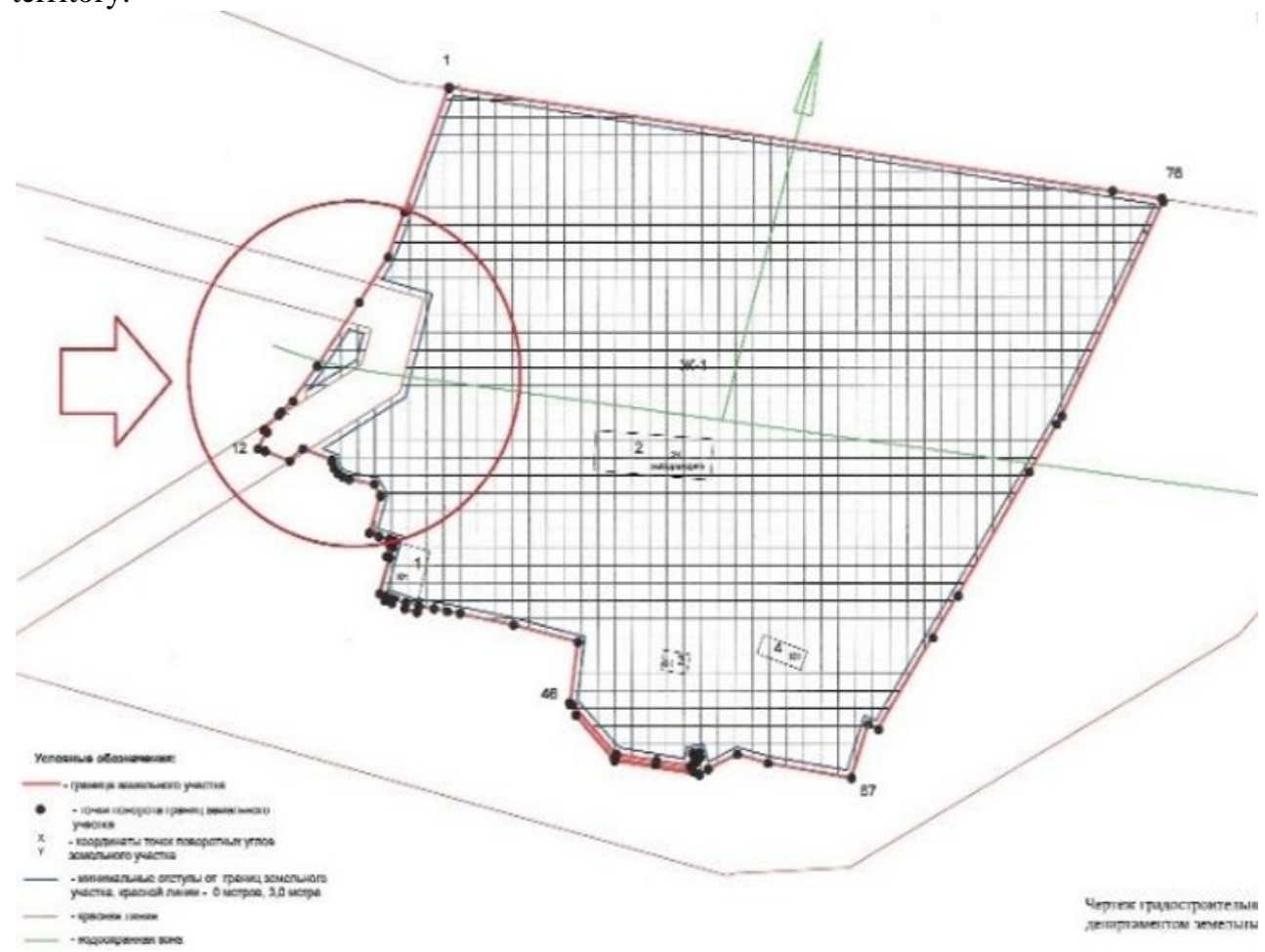

Fig. 1. A fragment of the urban development plan of the land, Source: Department of Land Relations and Urban Planning of the city of Tyumen

This microdistrict will be located in the central region and will have a beautiful picturesque view from the windows of the houses on the Turu River. However, water legislation sets out a number of requirements for construction near a water body.

In relation to the water body of the Tura River, the length of which is $1030 \mathrm{~km}$, a water protection zone $200 \mathrm{~m}$ wide from the location of the coastline, i.e. boundaries of the water body. When analyzing the drawing of the urban development plan of the land plot, one 
cannot fail to notice that the installed water protection zone cuts the land plot by about half, which, in turn, indicates limitations associated with the use of this land plot. An important aspect is that within the boundaries of water protection zones, design, construction, reconstruction, commissioning, operation of household and other facilities are allowed provided that such facilities are equipped with facilities that will protect water bodies from pollution, clogging, silting and depletion of water. [1]

In order to find out whether the new microdistrict will be equipped with special facilities to protect the water body, the positive conclusion of a non-state examination carried out by «Geoproekt» was examined, which indicates that there are documents on the connection conditions, technical conditions for water drainage.

Thus, the new microdistrict will be connected to a centralized drainage system (sewage), and the drainage of melt and storm water from the territory is provided for by the rain-water wells of the designed indoor storm sewer along the driveways, with subsequent connection to the existing storm sewer network. Also, in the conclusion, it is mentioned that the release of the internal drain will be performed on the relief in a concrete tray. [5]

In addition, analyzing the same urban development plan of the land plot for the residential microdistrict, one cannot fail to notice that the irregularly shaped land plot and its border are broken, as well as the existing red lines cut this land plot from the south-west side.

The conclusion of the non-state examination indicates that the relief of the construction site is relatively flat, sometimes artificially planned. Absolute elevations vary between 56.34 - $58.76 \mathrm{~m}$. The link between the natural topography and building conditions is ensured by the addition of a maximum height of $6.03 \mathrm{~m}$. [5] However, this fact may also have a negative impact on the built-up area.

During consultations with a doctor of technical sciences in the specialty "Foundations and foundations, underground structures" of the Department of Geotechnics at the Tyumen Industrial University, it was revealed that the site belongs to floodplain areas that are divided into various geotechnical categories of complexity (3 categories). For this type of territory, interbedded soils may be characteristic, or frequent interbedded soils, that is, when performing surveys in one place there may be a certain type of underground layer, and in another it may be absent. In addition, the dumping is able to shrink, and in this case a negative factor is triggered - there is friction on the piles, and then the soil, sinking, pull the piles down after it.

During construction in such territories, the type of territory should be taken into account and appropriate construction techniques should be used to protect the object from negative consequences.

In addition to all of the above, it is impossible not to mention that this territory was previously occupied by the Tyumen oil depot, which is confirmed by the 1951 map of the city of Tyumen and a fragment of the 2000 duty plan. According to the federal law of July 21, 1997 No. 116-FZ "On the industrial safety of hazardous production facilities", the Oil Depot is one of such facilities. 


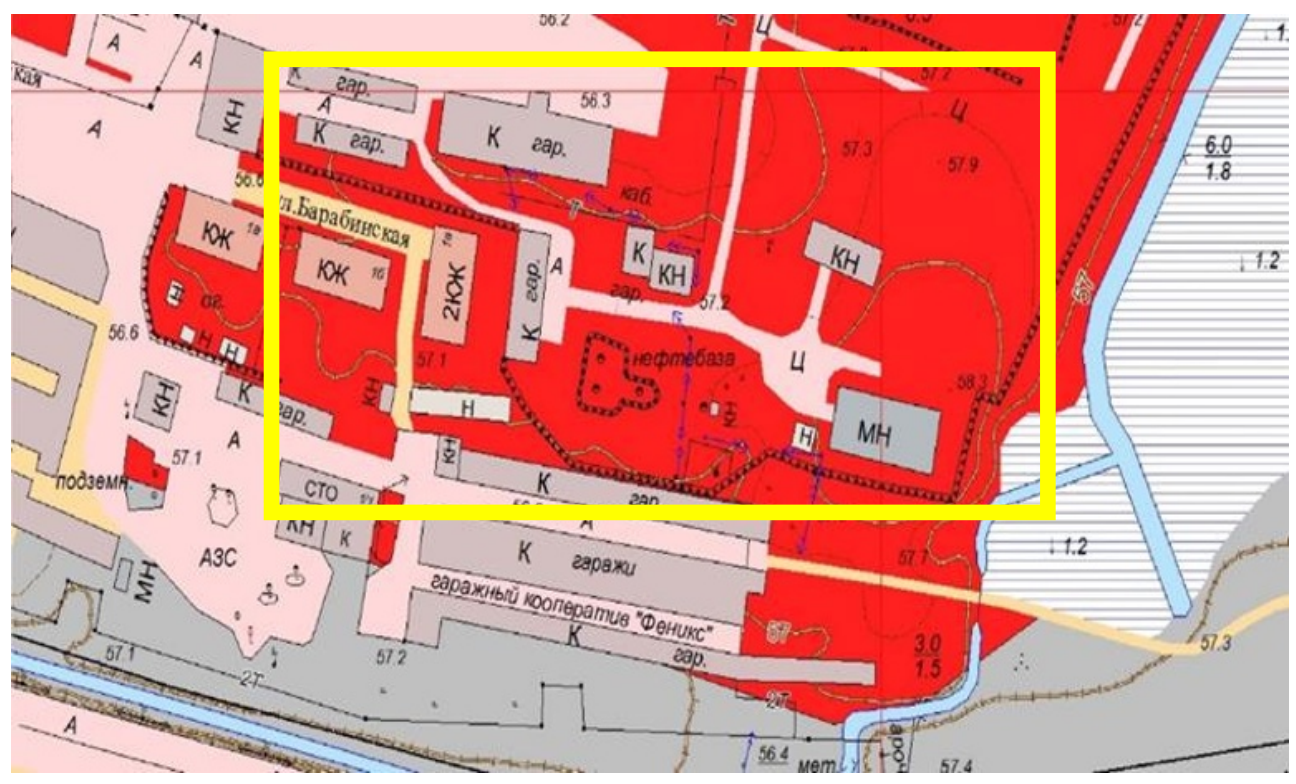

Fig. 2. A fragment of the duty plan in the city of Tyumen for 2000, Source: Department of Land Relations and Urban Planning of the city of Tyumen

It is not possible to determine exactly the hazard class of the Tyumen oil depot, since this object was mobilization and data on it are not disseminated. However, in the territory where automobile enterprises, oil depots and other facilities involved in the sale of fuel and lubricants were located, reclamation should be carried out, i.e. cleaning land from pollutants and restoration of the natural properties of the earth. This process implies a return to the original characteristics of all components violated by man, as a result of which the land is again suitable for use both for economic purposes and for development. Thus, there is a right to believe that the land plot under the former oil depot was necessary to be rehabilitated, since such a dangerous production facility could not but have an impact on it. Data on the restoration of this land are not available.

Regarding the reconstructed interchange at the intersection of ul. Melnikayte from the street Dambovskaya, which also affects the water body, in the approved documentation for the planning of the territory gives a specific designation that the project provides for the installation of two sets of treatment facilities for the treatment of storm drains coming from the designed transport interchange, the capacity of which will be 9 liters / second and 12 liters / give me a sec. The degree of purification of rainwater in sewage treatment plants must comply with the requirements for discharge into fisheries. As a measure of improvement, the documentation on the planning of the territory intended for the placement of linear objects of regional significance refers to the fact that the project on the planning of the territory provides for the installation of vertical acoustic noise-reflecting screens with a height of $6.0 \mathrm{~m}$ from the existing residential development. It turns out that the windows of the residential district will go exactly on these screens, which from an aesthetic point of view is not the desired landscape for the residents of this district. Another important feature that should be taken into account is the establishment of allotment lanes for roads, which is reflected in the federal legislation of the Russian Federation, according to which, within the boundaries of an allotment strip of a highway, it is prohibited:

1. Performance of work not related to construction, with reconstruction, overhaul, repair and maintenance of the road, as well as with the placement of road service facilities; 
2. Placement of buildings, structures, structures and other objects not intended for road maintenance, its construction, reconstruction, major repairs, repair and maintenance, and not related to road service objects;

3. Plowing of land, mowing grass, cutting and damage to forest stands and other perennial plantations, removal of turf and excavation, with the exception of work on maintaining the right of way or repairing the road, its sections;

4. Grazing animals, as well as their driving through roads outside specially designated places, agreed with the owners of roads;

5. Installation of advertising structures that do not meet the requirements of technical regulations and (or) regulatory legal acts on road safety;

6. Installation of information boards and signs that are not related to road safety or the implementation of road activities. [3]

As exceptions, it can be noted that land plots within the right of way of a road can be provided to citizens or legal entities for placement of road service facilities or for the installation and operation of advertising structures. In relation to such land plots, the establishment of private easements is allowed. On the basis of a private easement, it is allowed to use land plots at the border of the road right-of-way for the construction, reconstruction, overhaul of road service facilities, their operation, installation and operation of advertising structures.

\section{Conclusion}

The planning area is a large system of planning elements, the competent design and placement of which affects the dynamics of the urban environment. The features of the formation and development of each planning area and its individual elements should be taken into account at the stage of preparation of urban planning documentation, which, in turn, is a set of various documents: starting with urban planning and the development of a settlement and ending with the development prospects of free territories on the balance sheet: planning, land surveying, etc.

The following features of the territory were identified in the research results:

1. The complexity of the development of land located in floodplain areas, that is, in close proximity to a natural water body, consisting in the established requirements for the construction of the facility in the water protection zone;

2. Irrationality, fracture of the formed boundaries of the land plot and their intersection with established red lines;

3. Heterogeneity in the use and forms of ownership of adjacent land plots affects the timing of bringing the territory into line with the approved documentation for the planning of the territory;

4. Previous use of the land was carried out with the aim of operating a hazardous production facility.

5. In connection with the above, you can form the following sentences:

6. Optimize the design of the boundaries of the land plot in accordance with the current project of red lines, thereby setting the boundaries of the land plot so that the red lines do not intersect the land plot;

7. The need to take into account the previous use of the land in the conditions of the existing development and all the necessary measures for the further use of the territory in accordance with the established permitted use;

8. Give responsibility for the construction and further operation of the construction site as the developer himself, and the authorities that issued the building permit;

9. To place on the adjacent land plot intended for the construction of a publicbusiness center with a parking area for landscaping (without capital construction), which 
would provide greater protection for the residential district under construction from dust, noise and the influence of the main road, as well as increase the number of landscaped areas throughout the space of both the planning area and the settlement as a whole.

\section{References}

1. Public cadastral map on the official website of the Federal Service for State Registration, Cadastre and Cartography, https://rosreestr.ru/site/

2. Collection of publicly available information for students of different subject areas, http://studopedia.ru/

3. J. Gehl, Cities for people. Washington - Covelo - London, (2010)

4. L. Floridi, The philosophy of information, (2011).

5. Ch. Montgomery, Happy City: Transforming Our Lives through Urban Design (2013) 